Report A-857.1 is issued annually and shows the length of service of all employes on the pay rolls as of January 1. As indicated on the report, it shows the number of employes and the percentages to total number of employes for each of the periods indicated for the main divisions of the organization and the works as a whole.

\title{
THE EFFECT OF MOTION STUDY UPON THE WORKERS
}

By Frank B. Gilbreth, Mem. A. S. M. E.,

Consulting Management Engineer

and

Lilimian M. Gilbreth, Ph.D.

Motion study makes all activity interesting. While, at first thought, this fact may not seem of great importance, in reality it is the cause of many of the far-reaching results obtained through motion study. Motion study consists of analyzing an activity into its smallest possible elements, and from the results synthesizing a method of performing the activity that shall be more efficient,--the word "efficient" being used in its highest sense.

The process of motion study is such as to interest the worker. While undoubtedly some success could be made of motion study through a trained observer merely watching the worker, we find it of utmost importance and mutually advantageous from every standpoint, to gain the full and hearty coöperation of the worker at once, and to enlist him as a co-worker in the motion study from the moment the first investigation is made. Our methods of making motion study are by the use of the micromotion, simultaneous motion cycle chart, and chronocyclegraph methods. All make it imperative that the worker shall understand what is being done and why, and make it most profitable to every one that the worker shall be able, as well as willing, to help in the work of obtaining methods of least waste by means of motion study. While the process of making motion and time studies through the use of the cinematograph, the microchronometer and the cross-sectioned screen have been so reduced in cost as to make them indispensable 
even from the cost standpoint, the process is made even more economical when the worker, or the observed man, does his best work, and endeavors to take a part of active initiative in deriving the motion standards. We find in our practice that the worker is only too glad to do this. In fact, it is usually he, oftener than the observer, who cries out, "Wait a moment till this is done in the best way possible," or "Wait a moment, please, I know a way that I believe is easier." Similarly, when using the chronocyclegraph device; the worker is not only interested in the electric lights and their various paths and orbits of dots and dashes, but is most anxious that these paths shall be those of the greatest skill and the fewest number of motions possible.

The various methods used with these various types of apparatus, which are usually new to the worker, present problems in psychology which are interesting to the worker as well as to the observer. The worker is quick to note that, with the new conditions attending the measuring work, his own process varies for a short time at the beginning from his usual habits, because of the entering of the variables of the apparatus and the strange conditions that it involves. He is quick to notice, also, that this effect of strangeness soon disappears, and that he then works exactly in accordance with his normal method. This period of strangeness, far from being a disadvantage, is, on the contrary, often a great advantage. The worker is almost sure to revert to former habit, and an investigator or observer of ten gains valuable clues not only to excellent standards, but to necessary methods of teaching those standards, particularly with emphasis on eliminating interference of many wrong habits acquired in trade learning prior to conscious effort for motion economy. It is, therefore, clear that during the period of making motion studies the effect of them upon the worker is educative to the highest degree, for not only does he become interested in what he does, but he learns to think of all activity in terms of motions and elements of motions. The byproducts of this are also important, as he is always able afterwards to learn new work much faster and with comparatively little coaching, and as he has that success that usually attends the work of one who knows he knows the least wasteful method of attack of learning the new problems or solving the new task.

The effects of motion study are particularly striking upon the 
observer or the man actually making the studies. This is true not only during the time of making the observation, but also during the time spent in embodying the data derived in simultaneous cycle motion charts and in motion models. These motion models, which are wire representations of the paths of the motion, made from the stereoscopic records derived from the chronocyclegraph process have a peculiar educative value that is well embodied in the following statement of a young engineer who spent some time making motion models as a part of that thorough training for motion and time study man which we believe so necessary:

After making a number of models of motions I have changed from a scoffer to a firm believer. I believe not only in their value as an aid to the study of the psychology of motions, but also as to their educational value in the teaching of the motion study man.

I consider them of the same value to the motion study man as is the model of an engine or a mechanical device to an engineer. If the engineer was to study, for instance, a railroad engine, and the only chance he had to study was to watch an engine going by him at express train speed, his impression as to the mechanical working of the engine would be, to say the least, vague.

A motion, in itself, is intangible, but a model of a motion gives one an altogether different viewpoint, as it seems to make one see more clearly that each motion leaves a definite path, which path may be subjected to analysis.

I have made motion studies since making models, and what I learned from making the models has convinced me of their value. In former motion studies which I have made, my attention was always divided, more or less equally, between the direct distance between the starting and finishing points of the motion, the equipment, and the surroundings. I have found that, since seeing a motion, as represented by a model, I am better able to concentrate first on the motion itself, and then upon the variables which affect the motion. This seems to me a more logical method, and I know that I have had better results.

I believe a good method of illustrating how a motion model helps one to visualize is to compare it with the wake left by an ocean liner. When one stands at the stern of a liner, which changes its course often, and watches the wake he can visualize the changes more readily than when unable to see the wake.

It is interesting to note here not only the interest aroused intensively in the subject of motion study itself, but also extensively in the correlation of processes in the industries with general processes outside. The motion study man is a specialist who, because of his work, spends a large amount of time in the close study of motions, but to some extent this intensive and extensive interest is aroused in all those engaged in motion study, whether as observers or observed. 
After the results of motion study are actually installed the effects are as great or greater upon those who work under the derived standards. It must be understood that motion study always implies fatigue study,,$^{1}$ for the best and least wasteful results cannot be obtained otherwise, and that the worker who operates under these standards, therefore, not only has time to do the work in the best way, but ample time for adequate recovery from the fatigue of his work. This procedure provides directly for his physical and mental well-being. Motion study lays particular emphasis upon this. The great bogey of all who argue against standardization is "the awful resulting monotony." Now psychology, ${ }^{2}$ as well as the results in actual practice, proves that monotony comes not from performing the activity the same way every time, but from a lack of interest involved in, or associated with, the activity. This interest is supplied not only directly by motion study, but indirectly by the other parts of measured functional management, such as devices for eliminating unnecessary fatigue and for overcoming necessary fatigue.

Besides all this there is the interest aroused and the education resulting from the graphic representation of the results of motion study data to the worker as well as the observer. The pictures of the micromotion films are projected at the normal speed of the moving picture. They are also examined one at a time. The chronocyclegraphs in three dimensions are shown through the stereoscope, on the screen, by means of the wire motion models ${ }^{8}$ to the workers at the formen's and workers' meetings and are there discussed. All the traditional knowledge is literally collected, measured, sorted, tagged and labelled. This data, together with indisputable measuring methods are presented before those possessing the greatest craft skill of the old methods, and who can quickest actually learn the new knowledge and put it to use. The new knowledge is of no use to the employer without the coopperation of the worker. This fact puts the relations between the worker and his employer on a new basis. They must coöperate, or both pay an awful price. These new methods have demonstrated that

${ }^{1}$ See Fatigue Study, Sturgis and Walton, New York City.

${ }^{2}$ See The Psychology of Management, Sturgis and Walton, New York City.

${ }^{3}$ See "Motion Models: Their Use in the Transference of Experience and the Presentation of Comparative Results in Educational Methods, "-a paper presented at the American Association for the Advancement of Science. 
there is so much to learn that the employer cannot afford to put on and lay off his employees in proportion to the receipt of orders. He must solve the problem of steady employment. He cannot afford to let his specially trained men "get away." This is of vital importance in its effect upon the mental condition and activity of the worker.

By these means the workers, who are the actual producers of the nation, become familiar in every day experience with motion study and time study instruments of precision and with the results of their use. ${ }^{4}$ Such knowledge in the hands of our workers is the means of their being able to take the initiative in acquiring greater skill in all trades and in all life works. This is one of the best forms of industrial preparedness. It must be emphasized that the facts concerning motion study here stated embody not only a program but a record. The actual every day practice of motion study shows these effects upon the worker not only in the intangible results of added interest and a different attitude towards the work, but also in such tangible results as a larger number and a more profitable set of suggestions in the suggestion boxes, better attended and more profitable foremen's and workers' meetings, a greater number of promotions, more coöperation, more reading and study of the science of management, and higher wages earned with greater ease.

Motion study has no right to claim all the benefits that accrue from measured functional management, but, as a part of this management, it shares in these benefits, and thus those who work under it are assured of unusually high pay, during and after the motion study, a chance for promotion, physical and mental wellbeing, and a coöperative atmosphere in which to work. Motion study has the right to claim as its own benefits an added interest not only in the activity involved in the particular work done in the office or plant or wherever the work place may be, but in all activity away from as well as at work. It, therefore, benefits employee, as it does employer, as it does all those actively engaged in working under, or interested in it, in that it makes "to do," mean "to be interested," and to be interested means to be more efficient, more prosperous, and more happy.

"See "Motion Study and Time Study Instruments of Precision," Transactions International Engineering Congress, 1915. 